\title{
Síndrome de La Tourette: Revisão de literatura
}

\author{
Tourette syndrome: Review of literature
}

\section{Larissa Lane Cardoso Teixeira', José Mariano Soriano Pantoja Júnior', Francisco Xavier Palheta Neto², Mauricio Neres Targino', Angélica Cristina Pezzin Palheta 3 , Felipe Araújo da Silva4.}

1) Discente do quinto ano do curso de Medicina da Universidade do Estado do Pará.

2) Professor Adjunto da Universidade Federal do Pará e da Universidade do Estado do Pará, Preceptor da Residência Médica em Otorrinolaringologia do Hospital Universitário Bettina Ferro de Souza da Universidade Federal do Pará. Mestrado em Otorrinolaringologia pela Universidade Federal do Rio de Janeiro, Doutorado em Neurociências pela Universidade do Estado do Pará.

3) Professora Assistente da Universidade Federal do Pará e da Universidade do Estado do Pará, Preceptora da Residência Médica em Otorrinolaringologia do Hospital Universitário Bettina Ferro de Souza. Mestrado em Otorrinolaringologia pela Universidade Federal do Rio de Janeiro.

4) Discente do terceiro ano do curso de Medicina da Universidade do Estado do Pará.

Instituição: Centro de Otorrinolaringologia do Pará Belém / PA - Brasil.

Endereço para correspondência: Francisco Xavier Palheta Neto - Avenida Conselheiro Furtado, 2391, salas 1508 e 1608 - Bairro: Cremação - CEP: $66040-100$ - Belém / PA - Brasil - Telefone: (+55 91) 3249-9977 e (+55 91) 9116-0508 - E-mail: franciscopalheta@ hotmail.com

Artigo recebido em 11 de Março de 2010. Artigo aprovado em 21 de Abril de 2010.

\section{RESUMO}

Introdução: A Síndrome de La Tourette (ST) foi descrita pela primeira vez em 1825 e se trata de uma patologia neuropsiquátrica de início geralmente na infância, que acomete mais o sexo masculino, caracterizada por notável comprometimento psicológico e social, causando impacto na vida dos portadores e familiares. Até pouco tempo, essa patologia era considerada uma condição rara, porém, estudos atuais demonstram que a taxa de prevalência pode variar de $1 \%$ a $2,9 \%$ em alguns grupos.

Objetivo: Realizar uma revisão de literatura sobre os principais aspectos relacionados à Síndrome de La Tourette.

Síntese dos dados: A ST é um distúrbio genético, associado a alterações neurofisiológicas e neuroanatômicas, caracterizado por fenômenos compulsivos, cuja etiologia ainda é desconhecida. O quadro clínico é composto, principalmente, por tiques motores e vocais que se subdividem em simples e complexos. A sua associação com Transtorno Obsessivo Compulsivo e Transtorno do Déficit de Atenção e Hiperatividade é relativamente comum. O diagnóstico é eminentemente clínico e não existe, até o momento, nenhum teste laboratorial específico que confirme esta patologia. O tratamento é fundamentado, principalmente, na terapia psicológica. Porém, quando há necessidade do emprego de fármacos, os mais utilizados são os antagonistas dos receptores de dopamina.

Conclusão: A ST causa diversos prejuízos psicossociais e educacionais para o indivíduo e familiares. Porém, o diagnóstico e tratamento precoces são capazes de minimizar ou anular estes danos. Desta forma, conhecer os aspectos gerais que norteiam a ST é de fundamental importância para preservar a qualidade de vida dos portadores da doença.

Palavras-chave: síndrome de Tourette, tiques, otorrinolaringopatias, distúrbios da voz.

\section{SUMMARY}

Introduction: Tourette Syndrome (TS) was described for the first time in 1825, and it is a neuropsychiatry disease, initially begins in childhood, affects more males, characterized by remarkable social and psychological commitment, impacting the lives of patients and family. Until recently, this disease were considered a rare condition, but current studies show that the prevalence rate may vary in $1 \%$ to $2,9 \%$ in a few groups. Objective: Perform a review of literature over the main aspects related to Tourette syndrome.

Data synthesis: The TS is a genetic disorder, associated with neuroanatomical and neurophysiological alterations, characterized by compulsive phenomenon, whose etiology is still unknown. The clinical profile is composed, mostly, by motor tics and vocal tics, that which are divided in simple and complex. Its association with Obssessive Compulsive Disorder and Attention Deficit Hyperactivity Disorder is very commom. The diagnosis is mainly clinical and do not exist. Until now, there is no specific laboratory test that confirm this pathology. The treatment is based mainly on psychological theory. However when there is need for the use of drugs, the most widely used are the antagonists of dopamine receptors.

Conclusion: The TS causes many damages as psychosocial and educational for the individual and the family. However, the diagnosis and the early treatment are able to minimize or cancel this damages. This way, knowing the general aspects that guide the TS is of utmost importance to preserve the quality of life for the patients with the disease.

Keywords: Tourette syndrome, tics, otorhinolaryngologic diseases, voice disorders. 


\section{INTRODUÇÃO}

A primeira descrição de um paciente com tiques e comportamentos, que caracterizam a síndrome de Tourette (ST), ocorreu em 1825, pelo médico francês Jean Marc Gaspard Itard, que diagnosticou a maldição dos tiques na Marquesa de Dampierre (1).

Entretanto, somente em 1884, esta patologia recebeu o nome de síndrome de Gilles de la Tourette (ST), quando o aluno Gilles de la Tourette, no Hospital de la Salpêtrière, relatou a patologia como um distúrbio caracterizado por tiques múltiplos, incluindo o uso involuntário ou inapropriado de palavras obscenas (coprolalia) e a repetição involuntária de um som, palavra ou frase de outrem (ecolalia), baseado nos relatos do próprio ITARD $(2,3)$.

Houve tempos em que a ST era tida como uma maldição, e que quem a tinha estava condenado a manifestar comportamentos bizarros até o fim da vida. Évista ainda hoje, como uma perturbação que causa dificuldades de integração e por vezes inadaptação dos seus portadores nos vários contextos (4). Crianças e adolescentes que sofrem com a doença são frequentemente discriminadose possuem desvantagens em termos de desenvolvimento psicosocial. Essa condição pode contribuir para uma cronificação dos sintomas, assim como para o surgimento de outros transtornos de personalidade (5).

A ST consiste em uma patologia neuropsiquátrica de início na infância, caracterizada pelo comprometimento psicológico e social dos acometidos, causando impacto na vida dos portadores e familiares (3,6). Ela é geralmente associada ainda a uma variedade de problemas comportamentais e emocionais (7). É classificada no CID10 no grupo de Perturbações Emocionais e de Comportamento com início Habitualmente na Infância e Adolescência, com código F95.2 e descrita como Perturbação de tiques vocais e motores múltiplos combinados (8).

Até pouco tempo, essa patologia era considerada uma condição rara, comíndices de baixíssima incidência na população mundial (0,5/1000, em 1984) (9). Esse fato se devia provavelmente aos casos subdiagnosticados, já que este transtorno, na maioria das vezes, é de intensidade leve e muitos pacientes nem mesmo procuravam atendimento (10). Entretanto, tem-se observado, atualmente, através de estudos de prevalência, o aumento de sua incidência nos últimos anos $(6,11,12,13)$.

Estudos atuais demonstram que a taxa de prevalência pode variar de $1 \%$ a $2,9 \%$ em alguns grupos $(14,15)$. Dados estatísticos internacionais mostram que esta síndrome é encontrada em vários países, independentemente de clas- se social ou de etnia, acometendo cerca de três a quatro vezes mais o sexo masculino, em relação ao sexo feminino $(16,17,18)$. Estudos mostram que a prevalência de ST é dez vezes maior em crianças e adolescentes, sendo que, quando tiques são considerados isoladamente, a frequência aproximada varia de $1 \%$ a $13 \%$ nos meninos e $1 \%$ a $11 \%$ nas meninas (3). A razão para este aumento na detecção da incidência mundial da ST parece ser a melhoria na divulgação e no conhecimento das características clínicas da ST, entre os profissionais da área de saúde $(3,6,19)$.

Tendo em vista que a ST constitui um paradigma para um melhor entendimento da estreita relação existente entre a atividade cognitivo-emocional e a função motora, o presente estudo se propõe a abordar, de forma abrangente, diversos aspectos da ST, incluindo sua definição e etiologia, fisiopatologia, quadro clínico, patologias associadas, abordagem diagnóstica, diagnósticos diferenciais e tratamento.

\section{Definição e etiologia}

A ST é um distúrbio genético, de natureza neuropsiquiátrica, caracterizado por fenômenos compulsivos, que, muitas vezes, resultam em uma série repentina de múltiplos tiques motores e um ou mais tiques vocais, durante pelo menos um ano, tendo início antes dos 18 anos de idade $(20,21,22,23)$. Estes tiques podem ser classificados como motores e vocais, subdividindo-se, ainda, em simples e complexos. Geralmente, pacientes com ST apresentam, inicialmente, tiques simples, evoluindo para os mais complexos; entretanto, o quadro clínico pode variar de paciente para paciente $(24,25)$.

Os tiques são definidos como movimentos anormais, clônicos, breves, rápidos, súbitos, sem propósitos e irresistíveis. São exacerbados por situações de ansiedade e tensão emocional; atenuados pelo repouso e por situações que exigem concentração. Podem ser suprimidos pela vontade (por segundos ou horas), logo seguidos por exacerbações secundárias. Outras manifestações, tais como, ecolalia, ecopraxia, coprolalia e copropraxia podem, também, estar presentes (26).

A medida que o conhecimento acerca da ST se expande, torna-se cada vez mais óbvio que não se trata apenas de um distúrbio de movimento que se manifesta meramente através de tiques motores e vocais, mas que também é caracterizado por complexas alterações neurocomportamentais. A associação de hiperatividade com déficit de atenção (HDA) e transtorno obsessivo compulsivo (TOC) é relativamente comum. Dessa forma, o que é frequentemente apresentado como manifestação clínica pelos pacientes, representa apenas a ponta do iceberg $(26,27)$. 
Desde os anos 60, pesquisadores em todo o mundo vêm descrevendo novos aspectos desse transtorno. Sabese hoje que essa condição está associada a alterações neurofisiológicas e neuroanatômicas de etiologia, no entanto, ainda desconhecida. Há ainda inúmeras lacunas a serem esclarecidas tais como: um modelo neurobiológico preciso, o modo de transmissão genética e o espectro clínico desse transtorno (28).

Durante a última década, tem sido possível observar significativo progresso na investigação genética da etiologia da ST. Anormalidades cromossomiais em indivíduos e famílias portadoras da ST têm sido estudadas, no intuito de identificar genes como o gene A da monoamina-oxidase (MAOA) (29) e regiões cromossômicas comoa 18q22 (30), $17 q 25$ e 7q31 (29), que parecem estar envolvidas nesta patologia (31).

Neste processo de identificação, evidências sugerem que a ST seja um distúrbio genético de caráter autossômico dominante, visto a frequência de casos de tiques e manifestações obsessivo-compulsivas entre familiares desses pacientes, observada em estudos multicêntricos $(3,16,17)$. Até o presente momento, não foi possível identificar um marcador genético de forma definitiva para a ST (29).

O grau de concordância entre pares de gêmeos monozigóticos é maior do que 50\%, enquanto que, em pares de gêmeos dizigóticos, é de 10\%. Se forem incluídos gêmeos com tiques motores crônicos, o grau de concordância aumenta para 77-90\% entre os monozigóticos e para 30\% entre os dizigóticos. As diferenças entre os graus de concordância nos pares de gêmeos monozigóticos e dizigóticos indica que os fatores genéticos desempenham papel importante na origem da síndrome de Gilles de La Tourette (9).

Outros fatores também têm sido associados à patogênese da ST, tais como, o possível papel de infecções estreptocócicas no surgimento dos tiques. Em alguns casos, as reinfecções por Streptococcus estão diretamente associadas com a recorrência de sintomas neuropsiquiátricos (32). Estudos recentes sugerem que um processo inflamatório, em virtude de uma infecção aguda ou crônica, ou mesmo de uma resposta auto-imune pós-infecciosa, pode estar envolvido na patogênese da ST. Pesquisas à respeito da função do sistema imunológico na ST, tem encontrado no aumento da produção de anticorpos contra os gânglios basais, incluindo os anticorpos antifosfolípide e antineural, uma possível ligação com a gênese da síndrome (33).

Existem ainda possíveis indicações do envolvimento de infecções não-estreptocócicas na etiologia da ST, como a relação temporal entre infecções respiratórias virais e exacerbação de tiques (32). Segundo pesquisas, os tiques podem aparecer ou se encontrarem exacerbados na doença de Lyme aguda, infecções por Mycoplasmapıeumoniae, ou até mesmo no resfriado comum. Além disso, foi observada a atenuação ou remissão desses após antibioticoterapia. Esses achados sugerem que agentes infecciosos podem contribuir para a patogênese da doença (34). Entretanto estudos ainda estão sendo realizados para determinar a relação direta entre estes quadros infecciosos e a ST (3).

O traumatismo crânio-encefálico, a intoxicação por monóxido de carbono, o abuso de cocaína, a retirada de opiáceos ou o tratamento farmacológico com neurolépticos podem também se associar à gênese da síndrome. Há evidências de que o tratamento à longo-prazo com neurolépticos, pode elevar o risco de desenvolvimento de tiques em alguns pacientes. Esses são denominados de "touretismo" ou tiques secundários (9).

Eventos pré ou pós-parto também podem estar ligados à ST, onde a gravidade dos estressores durante a gestação tem sido analisada como fatores que poderiam contribuir para o desenvolvimento de distúrbios de tiques e patogênese da doença $(9,17)$. Dessa forma, devido ao fato de não se ter determinado, ainda, todos os fatores envolvidos no quadro neurológico anormal da ST, não se pode excluir a possibilidade da mesma ser uma síndrome multicausal.

\section{Fisiopatologia}

No que diz respeito à fisiopatologia da síndrome, importantes avanços têm ocorrido nos últimos anos, graças às informações provenientes de pesquisas envolvendo neuroanatomia, neurobiologia e estudos funcionais invivo através de ressonância nuclear magnética (RNM) (35).

Há consenso que, à nível cerebral, se distinguem vários circuitos neuronais paralelos, que dirigem informação desde o córtex até estruturas subcorticais (gânglios basais) e retornam a o córtex passando pelo tálamo, conhecidos como circuitos córtico-estriato-tálamo-corticais (CETC); estes são responsáveis por mediar a atividade motora, sensorial, emocional e cognitiva. Cogita-se que os pacientes com ST tenham uma deficiência na inibição destes circuitos, que a nível motor se expressa como tiques e compulsões, e a nível límbico e frontal como parte da sintomatologia obssessiva e défcit de atenção. Essa deficiência inibitória se reflete em uma hipersensibilidade aos estímulos tanto do meio interno como do meio externo $(10,35)$.

O estudo de imagens neurológicas tem possibilitado melhor entendimento sobre a base neural da ST, bem 
como, de sua provável patogênese (36). Diversas evidências do envolvimento do circuito córtico-estriato-tálamocortical e seus sistemas de neurotransmissão, associados com as características clínicas e comorbidades presentes na ST, têm sido amplamente divulgadas na literatura $(7,22)$.

A supressão de tiques em pacientes submetidos a leucotomias e talamotomias, pela interrupção do circuito CETC, apontam para o envolvimento direto deste na ST, sendo este fato observado através da visualização funcional da ressonância magnética, da análise das medidas de área do corpo caloso e pelo metabolismo da glicose e fluxo sanguíneo nas áreas corticais $(3,7)$.

Anormalidades nos volumes dos gânglios de base no corpo caloso também foram observadas em portadores com ST (3).Estudos de neuroimagem em adultos com a síndrome, sem realização de tratamento com antipsicóticos à longo-prazo, revelaram volumes significativamente menores dos núcleos caudato, lenticular e globo pálido quando comparados com grupo controle, tanto no lado direito como no lado esquerdo. Resultados similares foram encontrados em outros estudos, a compararem crianças com ST e grupos controle, observando diferença importante no volume do globo pálido esquerdo e assimetria lenticular (37).

Pesquisas envolvendo tomografias de emissão têm revelado ainda hipometabolismo e hipoperfusão em regiões do córtex frontal e temporal, no cíngulo, estriado e tálamo de pacientes com ST. Estas pesquisas de análise do metabolismo de glicose e do fluxo sanguíneo na região córtico-estriatal têm identificado anormalidades, principalmente envolvendo os gânglios da base éareas corticais destes indivíduos (3,9). Esses achados evidenciam que os distúrbios morfológicos e funcionais dos gânglios da base e circuito CETC, são fatores centrais para a persistência tanto dos tiques como dos sintomas obssessivo-compul$\operatorname{sivos}(37)$.

Do ponto de vista neuroquímico, diversas hipóteses sugerem o envolvimento do sistema dopaminérgico na patogênese da ST, visto que os neurolépticos, antagonistas da dopamina, são considerados efetivos no tratamento desta doença, por promover grande redução dos tiques. Por outro lado, os estimulantes como o metilfenidato, a cocaína, a pemolina e a L-dopa causam exarcebação dos tiques $(3,7)$.

Estudos imuno-histoquímicos têm sido ultimamente realizados na ST, particularmente os que se referem aos sistemas dopaminérgico, noradrenérgico e serotoninérgico (9). Com base nestes dados, a literatura sugere alguns mecanismos pelos quais o sistema dopaminérgico poderia estar envolvido, tais como, anormalidades na liberação de dopamina, hiperinervação dopaminérgica e a presença de receptores dopaminérgicos supersensíveis $(7,29)$.

A primeira hipótese, hipersensibilidade de D2, não foi confirmada, ou seja, não ficou demonstrado que oácido homovanílico, principal metabólito da dopamina, esteja reduzido no líquido cefalorraquidiano (LCR). A segunda, hiperinervação dopaminérgica do estriado, levaria ao aumento da concentração da dopamina (9). Um estudo recente, envolvendo análises pos-mortem de tecidos do córtex frontal e estriato, mostrou densidade elevada do receptor dopaminérgico D2 na região pré-frontal de pacientes com ST (3). Dessa forma, a hiperinervação levaria a estimulação aumentada do circuito CETC, sugerindo assim, que a ST esteja associada à falha da inibição dos minicircuitos CETC. Nesse contexto, as obsessões e a necessidade obsessiva por simetrias e exatitudes seriam o resultado da falha da inibição dos minicircuitos pré-frontais $(12,13)$.

O papel de outros neurotransmissores, tais como, acetilcolina, Gaba, sistema opioide endógeno, serotonina e norepinefrina $(13,17,23)$ vem sendo estudado, já que não se pode descartar o envolvimento de outros neurotransmissores dentro do circuito CSTC (23).

A evidência do envolvimento do sistema noradrenérgico na fisiopatologia da síndrome está baseada nos efeitos benéficos da clonidina e da guanfacina, os quais são tradicionalmente agonistas seletivos do receptor D2 adrenérgico. Já estudos no LCR de pacientes com ST, têm evidenciado redução do principal metabólito da serotonina, oácido hidroxi-indolacético. Em tecidos postmortem, estudos preliminares também têm mostrado que a serotonina está diminuída globalmente nos gânglios basais. Essa alteração metabólica, no entanto, está mais relacionada aos pacientes com TOC $(9,22)$.

\section{Quadro clínico}

O quadro clínico pode ser dividido em três categorias: tiques motores, tiques vocais e tique sensitivo.

Os tiques são definidos como movimentos anormais, clônicos, breves, rápidos, súbitos, sem propósitos e irresistíveis, que persistem durante o sono. São exacerbados por situações de ansiedade e tensão emocional; atenuados pelo repouso, relaxamento e por situações que exigem concentração. Podem ser suprimidos pela vontade (por segundos ou horas), logo seguidos por exacerbações secundárias $(3,38)$.

Os tiques acontecem diariamente, geralmente se apresentando em salvas, ocorrendo diversas vezes durante um único dia, porém eles podem se apresentar de maneira 
intermitente ao longo do ano (3). Há uma variação periódica no número, na frequência, no tipo e localização dos tiques, sendo que a intensidade dos sintomas também tem um caráter flutuante, podendo até desaparecer por semanas ou alguns meses $(11,12,39)$.

Além do notável prejuízo social causado pela presença dos tiques, em um trabalho realizado por MIRANDA (1999) (35), observou-se um caso de desprendimento de retina devido a tiques distônicos cervicais e fratura de costelas devido a tiques motores complexos, onde o paciente golpeava severamente seu tórax. Além disso, podem ocorrer também problemas ortopédicos (por flexionar os joelhos, virar excessivamente o pescoço ou a cabeça) e problemas cutâneos (por beliscar-se).

O início dos sintomas geralmente se manifesta durante a infância ou juventude, eventualmente atingindo estágios classificados como crônicos. Porém, no decorrer da vida adulta, frequentemente, os sintomas vão aos poucos se amenizando e diminuindo $(3,40,41)$.

\section{Tiques motores}

Os tiques motores classificam-se simples e complexos. Os primeiros envolvem contrações de grupos musculares funcionalmente relacionados (ex.: piscar os olhos e realizar movimentos de torção de nariz e boca), são abruptos, rápidos, repetidos e sem propósito, geralmente percebidos como involuntários (3). Incluem-se nesta classificação os tiques complexos, entretanto, são mais lentos, envolvem grupos musculares não relacionados funcionalmente, podem parecer propositados e são, por vezes, percebidos como voluntários. Os tiques motores complexos incluem imitação de gestos realizados por outrem, sejam eles comuns (ecocinese) ou obscenos (ecopraxia), além da realização de gestos obscenos (copropraxia) (35).

Os tiques motores simples mais frequentes são: piscamento dos olhos, desvios do globo ocular, caretas faciais, repuxar a cabeça, movimentos de torção do narize boca, estalar a mandíbula, trincar os dentes, levantar os ombros, movimento dos dedos das mãos, chutes, tensão abdominal ou de outras partes do corpo, sacudidelas de cabeça, pescoço, ou outras partes do corpo. Já os tiques motores complexos mais encontrados são: Gestos faciais, estiramento da língua, manutenção de certos olhares, gestos das mãos, bater palmas, atirar ou jogar um objeto, empurrar, tocar as pessoas ou coisas, pular, bater o pé, agachar-se, saltitar, dobrar-se, rodopiar ou rodar ao andar, girar, retorcer-se, posturas distônicas, desvios oculares, lamber mãos, dedos ou objetos, tocar, bater em ou analisar partes do corpo, outras pessoas ou objetos, beijar, arrumar, beliscar, escrever a mesma letra ou palavra, retroceder sobre os próprios passos, bater com a cabeça, morder a boca, os lábios ou outra parte do corpo, ecopraxia e copropraxia $(5,8,10,26,28,35)$.

$\mathrm{Na}$ maioria dos casos, os pacientes portadores de Síndrome de La Tourette apresentam, inicialmente, tiques simples, evoluindo para os mais complexos. Porém, o quadro clínico pode variar de paciente para paciente (3).

\section{Tiques vocais}

Os tiques vocais também se subdividem em simples e complexos. Os simples incluem a emissão de sons, tais como, o pigarrear, grunhidos, fungação e até gritos. Os complexos compreendem o uso involuntário ou inapropriado de palavras chulas ou obscenas (coprolalia), repetição de palavras ou frases (palilalia) e repetição involuntária das frases de outrem (ecolalia) (27,39). Observa-se, ainda, o uso repetido de palavras aleatórias, caracterizadas por sonoridade complexa ou exótica, arbitrariamente colocadas entre ou no meio das frases (42).

Dentre os principais tiques vocais simples estão coçar a garganta, fungar, cuspir, estalar a língua, cacarejar, roncar, chiar, latir, apitar, gritar, grunhir, gorgolejar, gemer, uivar, assobiar, zumbir, sorver e inúmeros outros sons. Já o ato de proferir sílabas, palavras ou frases fora do contexto ou inapropriadas, frases curtas e complexas, a palilalia, coprolalia e ecolalia, além de outras anormalidades da fala como bloqueio da fala, figuram-se entre os tiques vocais complexos mais comuns $(2,8,10,28,35)$.

\section{Tique sensitivo}

Otique sensitivoé definido como sensação somática nas articulações, nos ossos e nos músculos (peso, leveza, vazio, frio ou calor), que obrigam o paciente a executar um movimento voluntário para obter alívio. A sua presença não se faz obrigatória para o diagnóstico (3).

\section{Patologias associadas}

Pesquisas têm mostrado que indivíduos com SLT apresentam mais comorbidades psiquiátricas e consequentemente maiores prejuízos de funcionamento $(40,41)$.

Os sintomas mais comumente associados à Síndrome de La Tourette são obsessões e compulsões. Em um estudo clínico de 58 casos feito por Fen (2001) (28), foi encontrada associação com Transtorno Obsessivo Compulsivo em $39,6 \%$ dos casos.

Hiperatividade e distração também são relativamente comuns, sendo que muitos pacientes com SLT 
apresentam inicialmente sintomas do Transtorno do Déficit de Atenção e Hiperatividade (TDAH). Dessa forma, fazse necessário distinguir se sintomas de TDAH ocorrem no contexto da SLT ou se existe uma co-morbidade da SLT com TDAH (4).

Impulsividade e desconforto social com a sensação de estar sendo observado pelos outros, vergonha e humor deprimido também podem se manifestar juntamente com a SLT (3).

A presença de auto-agressividade pode alcançar até 30\% dos pacientes e os pacientes com SLT exibem uma maior incidência de fobias, transtornos de ansiedade e pânico que a população em geral (10).

Além de todo o exposto, o funcionamento social, acadêmico ou ocupacional pode estar prejudicado, em vista da rejeição pelos outros ou ansiedade quanto a ter os tiques em situações sociais, portanto, a síndrome em questão também pode associar-se ao Transtorno da Aprendizagem $(9,35)$.

\section{Diagnóstico}

O diagnóstico da Síndrome de La Tourette é eminentemente clínico, não existindo atualmente, nenhum teste laboratorial específico que confirme esta patologia (3). Porém, a Associação Americana de Psiquiatria (2002) (38), no intuito de sistematizar e facilitar o diagnósticos, criou os seguintes critérios:

A. Múltiplos tiques motores e um ou mais tiques vocais estiveram presentes em algum momento durante a doença, embora não necessariamente ao mesmo tempo.

B. Os tiques ocorrem muitas vezes ao dia (geralmente em ataques) quase todos os dias ou intermitentemente durante um período de mais de 1 ano, sendo que durante este período jamais houve uma fase livre de tiques superior a 3 meses consecutivos.

C. O início dá-se antes dos 18 anos de idade.

D. A perturbação não se deve aos efeitos fisiológicos diretos de uma substância (por ex., estimulantes) ou a uma condição médica geral (por ex., doença de Huntington ou encefalite pós-viral).

O diagnóstico de SLT deve ser feito cuidadosamente, pois $10 \%$ das crianças apresentam tiques em algum momento da vida $(3,4)$. Sendo assim, apesar dos exames complementares (EEG, tomografia ou análises sanguíneas) não serem úteis para firmar o diagnóstico de SLT, eles podem ser de grande valia no diagnóstico diferencial, uma vez que contribuem para a exclusão de outros distúrbios que possuem sintomas semelhantes (43).
Apesar dos exames de neuroimagem não serem empregados para o diagnóstico de certeza da SLT, um estudo com pacientes que não fizeram uso prolongado de antipsicóticos, demonstrou volumes diminuídos dos núcleos caudado e lenticular, comparado com o grupo controle. Ovolume do núcleo caudado demonstrou, ainda, ter valor preditivo com relação à severidade dos tiques em crianças $(33,34)$.

\section{Diagnóstico diferencial}

A Doença de Huntington, o acidente cérebrovascular, a síndrome de Lesch Nyhan, doença de Wilson, Coreia de Sydenham, esclerose múltipla, encefalite pósviral e traumatismo craniano são condições médicas que podem vir acompanhadas de movimentos anormais, que devem ser diferenciados dos tiques presentes na SLT. Além destas patologias, efeitos tóxicos diretos de uma substância também podem simular a presença de tiques $(38,44,45)$.

Os tiques também devem ser diferenciados dos movimentos estereotipados vistos no Transtorno de Movimentos Estereotipados e em Transtornos Invasivos do Desenvolvimento. A diferença entre eles nem sempre é fácil, mas em geral, os movimentos estereotipados parecem ser mais direcionados e intencionais, enquanto os tiques a presentam uma qualidade mais involuntária e não são rítmicos (38).

A SLT também deve ser diferenciada do Transtorno Obsessivo Compulsivo (TOC), patologia mais complexa, onde os movimentos são executados em resposta a uma obsessão ou de acordo com regras que devem ser rigidamente aplicadas (28). As compulsões são precedidas por preocupações persistentes, enquanto que os tiques são precedidos por tensões físicas transitórias numa parte do corpo. Porém, é válido salientar que a associação das duas patologias não é incomum, portanto, se existem os sintomas de ambas as perturbações, os dois diagnósticos podem ser justificados caso o quadro clínico se encaixe nos critérios diagnóstico de cada uma delas (4).

Certos tiques motores ou vocais presentes na Síndrome também devem ser diferenciados do comportamento desorganizado ou catatônico da Esquizofrenia.

Outros transtornos de tique, (Transtorno de Tique Motor ou Vocal Crônico, Transtorno de Tique Transitório e Transtorno de Tique Sem Outra Especificação) incluem-se também no diagnóstico diferencial da SLT (38).

Essas co-ocorrências de sintomas podem levar à confusão diagnóstica. Sendo assim, deve-se estar atento às peculiaridades do quadro clínico e evoluções 
particulares de cada doença e, ainda, ter conhecimento de que alguma delas podem ocorrer como co-morbidade $(40,41)$.

\section{Tratamento}

Devido às notáveis implicações socioculturais e educacionais que norteiam a SLT, é importante que o tratamento seja instituído o mais rápido possível, a fim de minimizar ou evitar danos ao paciente.

A escolha do tipo de tratamento deve ser apropriada para cada portador da ST, podendo incluir abordagens farmacológica e a psicológica (3). Esta última é de grande importância, uma vez que, além do tratamento psicoterápico do paciente, orienta pais, familiares e pessoas próximas ao mesmo, sobre as características da doença e o melhor modo de lidar com o indivíduo afetado (4).

A SLT não tem cura, sendo assim, o tratamento farmacológico é utilizado apenas para o alívio e controle dos sintomas a presentados. Devido a considerável número de efeitos colaterais, a abordagem farmacológica deve ser considerada somente quando os benefícios da intervenção forem superiores aos efeitos adversos (3). Além disso, a maioria dos pacientes não necessita de um tratamento específico para os tiques, bastando explicar a natureza do quadro e obom prognóstico na maioria dos casos, para os familiares, professores e pessoas próximas ao paciente (35).

Porém, quando se julga relevante o emprego de fármacos, os mais utilizados são os antagonistas dos receptores de dopamina, uma vez que diversos estudos sugerem que o bloqueio dos receptores dopaminérgicos tipo 2 é o ponto central para a eficácia do tratamento $(3,34)$.

O Haloperidol, um dos medicamentos mais utilizados para o tratamento SLT, apresenta uma série de efeitos colaterais, como sintomas extrapiramidais de características parkinsonianas, sedação, disforia, hiperfagia com ganho de peso e, discinesia tardia. A pimozida possui eficácia semelhante a o haloperidol sem o inconveniente dos efeitos extrapiramidais, porém apresenta efeitos colaterais envolvendo o sistema cardiovascular, incluindo ainda sedação e disfunção cognitiva $(3,10)$.

Atualmente, existe uma tendência a substituir os antagonistas típicos de receptores dopaminérgicos (ex.:haloperidol e pimozida), pelos antagonistas atípicos (ex.: risperidona, olanzapina e quetiapina) ou por agonistas dos receptores alfa-2-adrenérgicos (ex.:clonidina e a guanfacina), pois estes apresentam menor perfil de efeitos colaterais $(3,33,34,42)$.
A risperidona tem como principais efeitos colaterais a sedação, aumento de apetite e elevação dos níveis de prolactina. A olanzapina é uma boa alternativa para o controle dos sintomas agressivos e não possui efeitos colaterais graves, porém pacientes com problemas cardiovasculares e de epilepsia devem usá-lo com precaução, e pacientes com glaucoma devem evitá-lo $(3,33,34,42)$.

A clonidina e a guanfacina, vem se mostrando eficazes no tratamento da SLT, porém, por seres agentes anti-hipertensivos, deve ser feito um monitoramento da pressão arterial $(3,33,34,42)$.

As doses empregadas de cada fármaco devem ser individualizadas para atender a necessidade do paciente, causando-lhe o menor número de efeitos colaterais possíveis.

Alguns estudos demonstram que a injeção de toxina botulínica pode ser uma boa opção terapêutica para o tratamento de tiques motores e em alguns casos para tiques vocais (39). Experimentos mais recentes discutem ainda o emprego da terapia imunomoduladora e anti-inflamatória, bem como o uso da estimulação magnética transcraniana repetitiva, estimulação cerebral profunda e terapia eletroconvulsiva para o tratamento da SLT $(33,34)$.

\section{CONCLUSÃO}

A Síndrome de La Tourette é uma desordem que cursa com tiques motores e vocais significativos, causando causa diversos prejuízos socioculturais e educacionais para o indivíduo, sendo que os danos podem ser minimizados quando o diagnóstico e o tratamento são feitos precocemente. Desta forma, conhecer os aspectos gerais que norteiam a etiopatogenia, apresentação clínica e tratamento da doença em questão são indispensáveis.

\section{REFERÊNCIAS BIBLIOGRÁFICAS}

1. Itard JG. Mémoire sur quelques functions involuntaires des appeirls de la locomotion de la prehension et de la voix. Arch Gen Med 1825, 8:385-407.

2. Gilles de La Tourette GAB. Étude sur une affection nerveuse caractérisée par de Iincoordination motrice accompagnée décholaic et coprolalic. (Jumping, Latah, Myriachit). Arch Neurol. 1885, 9:19-42.

3. Loureiro NIV, Matheus-Guimarães C, Santos DO, Fabri RGF, Rodrigues CR, Castro HC. Tourette: por dentro da síndrome. Rev Psiquiatr Clín. 2005, 32(4):218-230. 
Disponível em: http://www.scielo.br/scielo.php?script= sci_arttext\&pid=S0101-60832005000400004\&lng=en.

4. Ramalho J, Mateus F, Souto M, Monteiro M. Intervenção educativa na perturbação Gilles De La Tourette. Rev Bras Educ Espec. 2008, 14(3):337-346. Disponível em: <http:/ /www.scielo.br/scielo.php?script=sci_arttext\&pid=S1413$65382008000300002 \& \operatorname{lng}=$ en\&nrm=iso $>$.

5. American Psychiatric Association. Diagnostic and Statistical Manual of Mental Disorders. 4th ed, Text Revision. Washington, DC: American Psychiatric Association; 2000.

6. Hounie A, Petribú K. Síndrome de Tourette revisão bibliográfica e relato de casos. Rev Bras Psiquiat. 1999, 21(1):50-63.

7. Singer HS, Minzer K. Neurobiology of Tourettes syndrome: concepts of neuroanatomic localization and neurochemical abnormalities. Brain \& Development. 2003, 25(1):S70-84.

8. Leckman JF, Cohen DJ. Tourettes Syndrome - Tics, Obsessions, Compuslions: Developmental Psychopathology and Clinical Care. New York, NY:Wiley; 1999.

9. Mattos JPD, Mattos VMDBC. Doença dos tiques: aspectos genéticose neuroquímicos atuais. Arq. Neuro-Psiquiatr. 1999, 57(2B): 528-530. Disponível em: http://www.scielo.br/ scielo.php?script=sci_arttext \&pid=S0004282X1999000300029\&lng=en.

10. Miranda M. Tics, Obsesiones y Síndrome de Gilles de la Tourette: Actualización Clínica. Rev. chil. Neuro-psiquiatr. 2000, 38(2): 112-121. Disponível em: http://www.scielo.cl/ scielo.php?script=sci_arttext\&pid=S0717$92272000000200006 \& \operatorname{lng}=$ es.

11. Robertson MM, Stern, JS. Tic disorders: new development in Tourette syndrome and related disorders. Curr Opin Neurol. 1998, 11(4):373-80.

12. Robertson MM. Diagnosing Tourette syndrome: is it a common disorder? J Psychosom Res. 2003, 55(1):3-6.

13. Eapen V, Foxhiley P, Banerjee S, Robertson M. Clinical features and associated psychopathology in a Tourette syndrome cohort. Acta Neurol Scand. 2004, 109(4):255-60.

14. Kadesjo B, Gillberg C. Tourettes disorder: epidemiology and comorbidity in primary school children. J Am Acad Child Adolesc Psychiatry. 2000, 39(5):548-55.

15. Freeman RD, Fast DK, Burd I et al. An international perspective on Tourette syndrome: selected findings from
3500 Individuals In 22 Countries. Dev Med Child Neurol. 2000, 42(7):436-47.

16. Robertson MM. Tourette syndrome, associated conditions and the complexities of treatment. Brain. 2000, 123(3):42562.

17. Scahill L, Tanner C, Dure L. The epidemiology of tics and Tourette syndrome in children and adolescents. Adv Neurol. 2001, 85:261-71.

18. Mason A, Banerjee, SP, Eapen V, Zeitlin H, Robertson MM. The prevalence of Gilles de la Tourettes syndrome in a mainstream school population. A pilot stud. Dev Med Child Neurol. 1998, 40(5):292-6.

19. Kushner HI. Medical fictions: the case of the cursing marquise and the (re)construction of Gilles de la Tourttes syndrome. Bull Hist Med. 1995, 69(2):224-54.

20. American Psychiatry Association. Diagnostic and Statistical Manual of Mental Disorders, 4th edition (DSM IV), American Psychiatry Association, Washington, DC, 1994.

21. World Health Organization. International classification of diseases and health related problems, 10th revision, World Health Organization, Geneva, 2000.

22. Peterson BS. Neuroimaging studies of Tourette syndrome: a decade of progress. Adv Neurol. 2001, 85:17996.

23. Pauls DL. An update on the genetics of Gilles de la Tourette síndrome. J Psychosom Res. 2003, 55(1):7-12.

24. Leckman JF, Peterson BS, King RA et al. Phenomenology of tics and natural history of tic disorders. Adv Neurol. 2001, 85:1-14.

25. Mercadante MT, Rosario MCC, Quarantini LC, Sato FP. The neurobiological bases of obsessive compulsive disorder and Tourette syndrome. J Pediatr. 2004, (2 Suppl):S3544.

26. Mattos JP, Rosso ALZ.Tiques e síndrome de Gilles de La Tourette. Arq Neuropsiquiatr. 1995, 53:141-146.

27. Jankovic J. Phenomenology and classification of tics: Tourette syndrome. Neurol Clin N Am. 1997, 15:267-275.

28. Fen CH, Barbosa ER, Constantino ME. Síndrome de Gilles de la Tourette: estudo clínico de 58 casos. Arq. NeuroPsiquiatr. 2001, 59(3B):729-732. Disponível em: http:// www.scielo.br/scielo.php?script=sci_arttext\&pid=S0004282X2001000500015\&lng=en. 
29. Díaz-Anzaldúa A, Joober R, Riviere JB et al. Tourette syndrome and dopaminergic genes: a family-based association study in the French Canadian founder population. Mol Psychiatry. 2004, 9(3):272-7.

30. Cuker A, State MW, King RA, Davis N, Ward DC. Candidate locus for Gilles de la Tourette syndrome/ obsessive compulsive disorder/chronic tic disorder at 18q22. Am J Med Genet A. 2004, 130(1):37-9.

31. State MW, Greally JM, Cuker, A et al. Epigenetic abnormalities associated with a chromosome 18(q21-q22) inversion and a Gilles de la Tourette syndrome phenotype. Proc Natl Acad Sci USA. 2003, 100(8):4684-9.

32. Hoekstra PJ, Anderson G, Limburg PC et al. Neurobiology and neuroimmunology of Tourettes syndrome: an update. Cell. Mol. Life Sci. 2004, 61:886-98.

33. Muller N, Riedel M, Straube A, Wilske B. Poststreptococcal autoimmune phenomena in patients with Tourette Syndrome. Psychiatry Res. 2000, 94:43-49.

34. Muller N, Riedel M, Blendinger C, Oberle K, Jacobs E, Abele-Horn M. Mycoplasma pneumoniae infection and Tourettes syndrome. Psychiatry Res. 2004, 129:119-125.

35. Miranda MC, Menéndez PG, David PG, Troncoso MS, Hernández MC, Chaná PC. Enfermedad delos tics (síndrome de Gilles de la Tourette): características clínicas de 70 pacientes. Rev. méd. Chile.1999, 127(12): 1480-1486. Disponible en: http://www.scielo.cl/scielo.php?script= sci_arttext\&pid=S0034-98871999001200010\&lng=es.

36. Gerard E, Peterson BS. Developmental processes and brain imaging studies in Tourette syndrome. J Psychosom Res. 2003, 55(1):13-22.

37. Bloch MH, Leckman JF, Zhu H, Peterson BS. Caudate volumes in childhood predict symptom severity in adults with Tourette syndrome. Neurology. 2005, 65:12531258.
38. Associação Americana de Psiquiatria. Manual de Diagnóstico e Estatística das Perturbações Mentais - DSMIV-TR. 4ª ed. Lisboa: Climepsi, 2002.

39. KimaidPAT, Quagliato EMAB, Crespo AN, Wolf A, Viana MA, Resende LAL. Laryngeal electromyography in movement disorders: preliminary data. Arq. Neuro-Psiquiatr. 2004, 62(3a):741-744. Disponível em: http:// www.scielo.br/scielo.php?script=sci_arttext\&pid=S0004282X2004000400034\&lng=en.

40. Burd L, Kerbeshian J. Gilles de la Tourettes syndrome and bipolar disorder. Arch Neurol. 1984, 41(12):1236.

41. Robertson MM. Mood disorders and Gilles de la Tourettes syndrome: An update on prevalence, etiology, comorbidity, clinical associations, and implications. J Psychosom Res. 2006, 61(3):349-58.

42. Alzuri FM, Valdés MR. Trastorno de Gilles de la Tourette: aspectos patogénicos y terapéuticos. Presentación de 1 caso. Rev Cubana Pediatr. 2001, 73(1):64-68. Disponível em: http:/ /scielo.sld.cu/scielo.php?script=sci_arttext\&pid=S003475312001000100011\&lng=es.

43. Boarati MA, Castillo AR, Lage G, Castillo JCR, Lee FI. Síndrome de Gilles de La Tourette em criança portadora do transtorno do humor bipolar. Rev Bras Psiquiatr. 2008, 30(4):407-408. Disponível em: http://www.scielo.br/ s c i e lo.ph p? s c ript $=$ s ci_art text \& pi d $=$ S151644462008000400024\&lng=en.

44. Jankovic, J. Differential diagnosis and etiology of tics. Adv Neurol. 2001, 85:15-29.

45. Holguín JA, Osío OU, Sánchez YM, Carrizosa JM, Cornejo WO. Comorbilidad del trastorno de hiperactividad con déficit de atención (THDA) en una muestra poblacional de niños y adolescentes escolares, Sabaneta, Colombia, 2001. Iatreia. Rev Fac Med Univ Antioqui. 2007, 20(2):101-110. Disponívelem: http://www.scielo.org.co/scielo.php?script= sci_arttext\&pid=S0121-07932007000200001\&lng=en . 